\title{
A HUGE PEDUNCULATED CERVICAL FIBROID POLYP WITH SEPSIS- A CASE REPORT
}

\author{
Sunita Kanash ${ }^{1}$, Priscilla Savita², Manju Parmar ${ }^{3}$ \\ ${ }^{1}$ Senior Resident, Department of Obstetrics \& Gynaecology, AIMS \& SKS Hospital, Bhopal. \\ ${ }^{2}$ Assistant Professor, Department of Obstetrics \& Gynaecology, AIMS \& SKS Hospital, Bhopal. \\ 3Senior Resident, Department of Obstetrics \& Gynaecology, AIMS \& SKS Hospital, Bhopal.
}

\section{ABSTRACT}

\section{BACKGROUND}

We are presenting a case of a 38-year-old multiparous woman who presented to the emergency unit with a huge infected mass protruding per vaginum, bleeding per vaginum, foul smelling discharge, fever and severe pallor. After careful investigation, it was labelled as a case of pedunculated cervical fibroid polyp. The polypectomy was carried out, and the patient had an uneventful postoperative stay.

\section{KEYWORDS}

Cervical Fibroid Polyp, Leiomyoma, Pedunculated.

HOW TO CITE THIS ARTICLE: Kanash S, Savita P, Parmar M. A huge pedunculated cervical fibroid polyp with sepsis - A case report. J. Evolution Med. Dent. Sci. 2016;5(99):7305-7306, DOI: 10.14260/jemds/2016/1653

\section{BACKGROUND}

The leiomyoma is one of the most common tumour of all the uterine and pelvic tumours. The incidence of leiomyoma is about $20 \%$ in the reproductive age group, and of which about $1-2 \%$ are confined to the cervix. ${ }^{1}$ The pedunculated fibroids are connected to the myometrium by a narrow stalk and "float" in the abdominal cavity or through the cervical os in the vagina. Cervical leiomyomas can also present as introital polypoid masses. ${ }^{2}$ The cervical fibroid polyp usually arises from the ectocervix and from the posterior lip of the ectocervix. The cervical fibroid polyp is normally small and usually single in number. At times, it is big enough to distend the vagina or even comes out of the introitus. The cervical fibroid polyp is a common pathology in the female adult population but they are usually small with most measuring less than $2 \mathrm{~cm},(3,4,5)$ hence they are often in incidental findings on routine vaginal examination. ${ }^{6}$ The patients present with a vaginal mass usually infected and necrotic. There are different approaches to the treatment of pedunculated prolapsed myomas and there are reports about its management in the literature. ${ }^{7}$ We present a case of a woman with a huge pedunculated cervical fibroid polyp, necrotic, infected, with severe anaemia, treated by vaginal polypectomy with good prognosis.

\section{CASE}

A 38-year-old woman, para 3, living 3, presented to the emergency unit of the Department of Obstetrics and Gynaecology at SKS Hospital, with history of something coming out per vaginum with heavy vaginal bleeding, fever, difficulty in walking and fatigue from seven days. She had 2 years' history of foul smelling vaginal discharge. A week before coming to hospital, she developed heavy bleeding during micturition. She felt something coming out per vagina.

Financial or Other, Competing Interest: None.

Submission 05-11-2016, Peer Review 29-12-2016,

Acceptance 05-12-2016, Published 12-12-2016.

Corresponding Author:

Dr. Sunita Kanash,

Resident Doctors Hostel, SKS Hospital,

Inayatpur, Kolar Road, Bhopal.

E-mail: kanash_sunita@yahoo.com

DOI: $10.14260 /$ jemds/2016/1653
She didn't have any menstrual complaints and her current clinical finding were severe pallor, fever (Temperature 39.6), Tachycardia. Abdomen was flat, soft, nontender. On pelvic examination, on inspection, a huge fungating fleshy mass of size $25 \times 20 \times 14 \mathrm{~cm}$ with infected, marked degeneration, necrosis sloughed surface was seen out of the vagina. It was foul smelling, blackish brown in colour, hard in consistency and pedunculated about 5-6 cm (Figure 1).

Her examination reports showed haemoglobin $5.4 \mathrm{~g} \%$, WBC 18300/cu. mm, platelet count 4.35 lakh/cu. mm, haematocrit $17 \%$, blood group B positive. Renal and hepatic function tests and other requisite biochemical parameters were in normal range. On ultrasonographic examination, findings included uterus anteverted, bulky, both ovaries appeared normal, with normal endometrial lining, vagina full of echogenicity and mass arising from the cervix suggestive of cervical fibroid.

She was admitted and started on broad-spectrum antibiotics, valval toileting with antiseptics and saline irrigation of the mass. She was transfused with 4 units of packed cell volume preoperatively. Post-transfusion haemoglobin level was $7.8 \mathrm{~g} \%$, haematocrit value $23.6 \%$. She was taken for surgery after controlling sepsis. Polypectomy was carried out, the pedicle was $5 \mathrm{~cm}$ diameter in width, we clamped and ligated, checked haemostasis and vaginal packing was carried out. Grossly, the mass measured $25 \times 20 \times 14 \mathrm{~cm}$ after removal and weighed $1.8 \mathrm{~kg}$. Cut section was smooth, reddish white, whorl-like appearance, with presence of degenerative changes (Figure 2). Post-operative daily vaginal douche was carried out with the Betadine solution. Histopathology confirmed the mass to be a benign leiomyoma and there were no malignant changes. The patient had an uneventful post-operative recovery.

\section{DISCUSSION}

Leiomyomas arise from a single neoplastic cell within the smooth muscle of the uterine myometrium. ${ }^{8}$ The cervical fibroids with excessive growth are uncommon. They are grossly and histologically identical to those found in the corpus. The cervix is lowermost part of the uterus, cylindrical in shape and measures about $2.5 \mathrm{~cm}$ length and diameter is divided into a supravaginal part - the part lying above the vagina and a vaginal part which lies within the vagina, each 
measuring $1.25 \mathrm{~cm}$. In the supravaginal part of the cervix, it may be interstitial or subperitoneal variety and rarely polypoidal. Depending upon the position, it may be anterior, posterior, lateral or central. The cervical fibroid arises from the vaginal part of the cervix and is usually pedunculated and rarely sessile. Previous reports indicate that giant cervical polyps originate more often from the ectocervix and rarely from the endocervix in contrast to the commonly seen cervical polyps. ${ }^{9}$ USG has been considered as the primary diagnostic tool. The MRI increases the precision of which number, size, and location of myomas are identified and has more sensitivity than ultrasound.10 The cervical fibroids are difficult to manage, mostly because of inaccessibility, distortion of anatomical structures and hence there is an increased risk of damaging uterine vessels, ureter and bladder. The presence of this huge fungating mass at the introitus in this patient was confusing; neglected procidentia with cervical hypertrophy. Our case with large cervical fibroid presented only with menorrhagia and fever without any pressure effect.

The patient had foul smelling vaginal discharge since 2 years, but she did not seek any medical help and was presented in emergency with a huge infected cervical fibroid polyp protruding at introitus with features of sepsis and anaemia. If the patient would have taken medical help earlier, such complications could have been prevented.

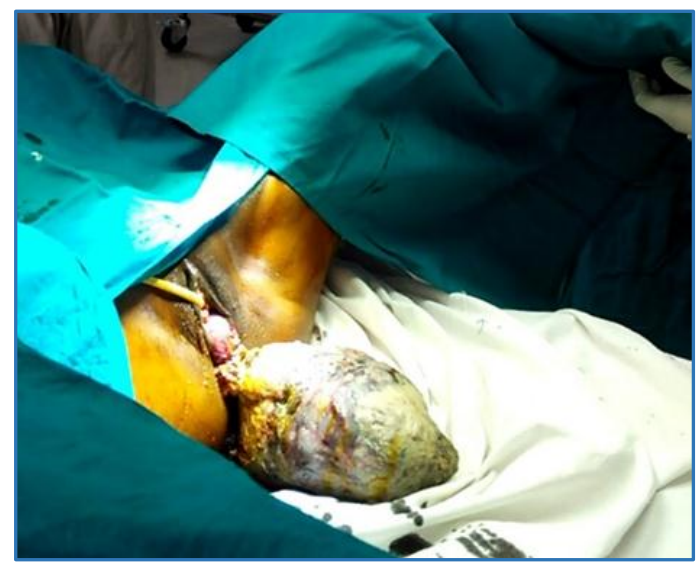

Figure 1. A Pedunculated Cervical Fibroid Polyp at Introitus

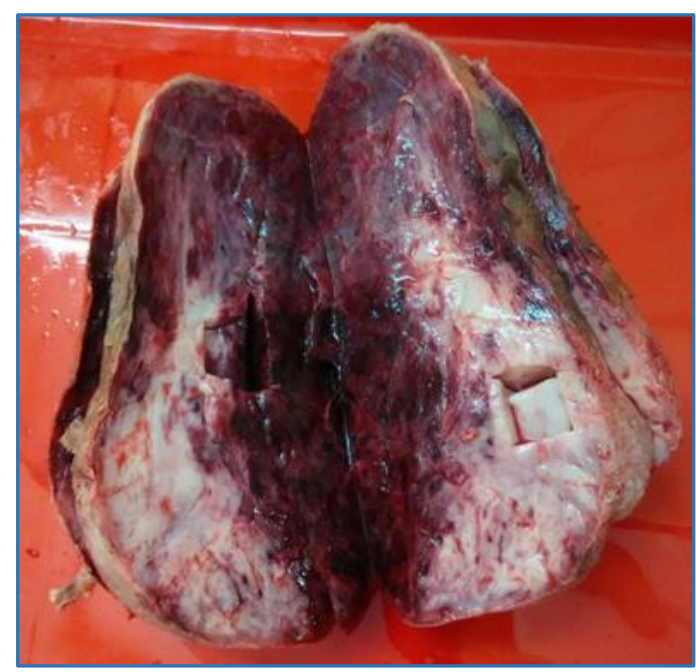

Figure 2. Polypectomy Specimen of Pedunculated Cervical Fibroid Polyp

\section{CONCLUSION}

Although huge pedunculated cervical fibroid-polyp is rare, and their management can be quite challenging, a proper evaluation is needed to make an accurate diagnosis. In this case, we have presented a huge, prolapsed, pedunculated fibroid polyp with sepsis in a woman, treated by polypectomy. The polypectomy is an easy, safe and effective procedure.

\section{REFERENCES}

1. Bhatla N. "Tumours of the corpus uteri". In Jeffcoates Principles of Gynaecology. 5 ${ }^{\text {th }}$ ed. London: Arnold Publisher 2001:470.

2. Nanda S, Sangwan K, Gulati N. Giant cervical polyp. Trop Doct 1998;28(2):112-3.

3. Abramovici H, Bornstein J, Pascal B. Ambulatory removal of cervical polyps under colposcopy. International Journal of Gynaecology \& Obstetrics 1984;22(1):47-50.

4. Khalil AM, Azar GB, Kaspar HG, et al. Giant cervical polyp. A case report. Journal of Reproductive Medicine 1996;41(8):619-21.

5. Terruhn V. Polyps of the uterine cervix during the hormonal resting phase in childhood. Geburtshilfe Frauenheilkd 1977;37(1):35-8.

6. Amesse LS, Taneja A, Bronxson E, et al. Protruding giant cervical polyp in a young adolescent with previous rhabdomyosarcoma. Journal of Pediatric \& Adolescent Gynecology 2002;15(5):271-7.

7. Faivre E, Surroca MM, Deffieux $X$, et al. Vaginal myomectomy: literature review. Journal of Minimal Invasive Gynecology 2010;17(2):154-60.

8. Cincinelli E, Romano F, Anastasio PS, et al. Transabdominal sonohysterography, transvaginal sonography, and hysteroscopy in the evaluation of submucous myomas. Obstetrics \& Gynecology 1995;85(1):42-7.

9. Leley L, Breech, Rock JA. Te Linde's Operative Gynaecology. Chapter 31. Leiomyomata uteri and myomectomy. $10^{\text {th }}$ edn. 2014:687-724.

10. Kaur AP, Saini AS, Kaur D, et al. Huge cervical fibroid: an unusual presentation. Journal of Obstetrics and Gynaecology of India 2002;52(1):164-5. 